\title{
Characterisation of Laser System Power Draws in Materials Processing
}

\author{
Nicholas Goffin ${ }^{1}\left(\mathbb{D}\right.$, Lewis C. R. Jones ${ }^{1}\left(\mathbb{D}\right.$, John $^{\text {Tyrer }}{ }^{1}$, Jinglei Ouyang ${ }^{2}$, Paul Mativenga ${ }^{2}$ and \\ Elliot Woolley ${ }^{1, *(\mathbb{D})}$
}

1 Wolfson School of Mechanical and Manufacturing Engineering, Loughborough University, Leicestershire LE11 3TU, UK; N.Goffin@lboro.ac.uk (N.G.); L.Jones@lboro.ac.uk (L.C.R.J.); J.R.Tyrer@lboro.ac.uk (J.T.)

2 School of Mechanical, Aerospace and Civil Engineering, The University of Manchester, Manchester M13 9PL, UK; jinglei.ouyang@manchester.ac.uk (J.O.); P.Mativenga@manchester.ac.uk (P.M.)

* Correspondence: E.B.Woolley@lboro.ac.uk; Tel.: +44-01509-225410

Received: 31 March 2020; Accepted: 18 May 2020; Published: 19 May 2020

\begin{abstract}
Due to their high speed and versatility, laser processing systems are now commonplace in many industrial production lines. However, as the need to reduce the environmental impact from the manufacturing industry becomes more urgent, there is the opportunity to evaluate laser processing systems to identify opportunities to improve energy efficiencies and thus reduce their carbon footprint. While other researchers have studied laser processing, the majority of previous work on laser systems has focused on the beam-material interaction, overlooking the whole system viewpoint and the significance of support equipment. In this work, a methodical approach is taken to design a set of energy modelling terminologies and develop a structured power metering system for laser systems. A $300 \mathrm{~W}$ fibre laser welding system is used to demonstrate the application of the power characterization system by utilizing a purpose-built power meter. The laser is broken down according to sub-system, with each part analysed separately to give a complete overall power analysis, including all auxiliary units. The results show that the greatest opportunities for efficiency improvements lie in the auxiliary units that support the laser devices as these were responsible for a majority of the electrical draw; $63.1 \%$ when the laser was operated at $240 \mathrm{~W}$, and increasing as the beam power reduced. The remaining power draw was largely apportioned to electrical supply inefficiencies. In this work, the laser device delivered a maximum of $6 \%$ of the total system power. The implications of these results on laser processing system design are then discussed as is the suitability of the characterization process for use by industry on a range of specific laser processing systems.
\end{abstract}

Keywords: laser processing; energy consumption; sustainability; environmental impact; manufacturing process; emissions

\section{Introduction}

Within the manufacturing industry, there is a need to improve energy efficiency in order to reduce both process costs and carbon footprints. As of 2016, the UK industrial sector accounts for $21 \%$ of the total delivered energy and $29 \%$ of $\mathrm{CO}_{2}$ emissions [1], and it is now a legal requirement to achieve net-zero carbon emissions by 2050 [2]. Similar environmental impacts of manufacturing are found internationally, with industry consuming approximately $25 \%$ of the total available energy in the European Union [3], and contributing $22 \%$ of all greenhouse gas emissions in the USA [4].

An improved assessment and the utilisation of new and more intensive industrial processes are some of the strategies for achieving carbon reduction [5]. This target drives all sectors, and a significant body of literature exists that enables the modelling of generic processes and suggests ways to process 
and interpret the results. Models are useful, but there can be some void between a generic approach and the ability to implement them for specific types of manufacturing technology. This paper addresses a disconnect between available models and the need to improve the energy efficiency of laser processing techniques, demonstrates the concept and highlights how this indicates areas of improvement in energy efficiency. Laser processing systems encompass a number of specific energy consumers that need to be addressed with respect to their individual characteristics.

\subsection{Energy Modelling}

Laser manufacturing processes are often chosen due to their high energy density [6], but when comparing newer laser processes to older, more conventional processes, lasers are shown to be more energy-intensive [7]. An initial analysis of laser cutting has shown that there is significant potential to increase energy efficiency in these types of processes [8]. This paper will characterise the system energy consumption specifically for laser-based manufacturing to identify where energy is consumed. The first step is to review which energy modelling frameworks can be applied to laser systems.

Kellens et al. [9] proposed a framework for a systematic life-cycle analysis of manufacturing emissions. The framework contains different types of studies in sequence, e.g., a time study to identify machine production modes and their relative magnitudes, followed by a power study which incorporates supplied power to calculate the energy draw of each production mode. The framework also gives an overview of different production modes and the mathematical relationship between them. What it does not do, however, is go into detail on the components of the system/sub-system breakdown. This is done by Duflou et al. [10], by showing that, in addition to the time-based operating mode breakdown, manufacturing systems could be also be sub-divided into various levels of interest, from individual components to a global scale: the device/unit level, the line/cell/multi-machine level, the facility level, the multi-factory level and the enterprise/global supply chain level. These levels can effectively encompass the entire global manufacturing system, and efficiency improvements can be made in any one of them. These two frameworks $[9,10]$ provide useful methods for categorising where energy consumption within a manufacturing system goes but do not give specific details on electrical consumption.

An analysis of manufacturing processes and their electricity consumption was carried out by Rodrigues et al. [11], identifying areas where it could be reduced. While not specific to laser processing, this allowed the identification of elements such as idle machines and possible modifications to operational routines which are generic to all manufacturing processes. In addition to this, Bajpai et al. [12] specifically investigated energy bottlenecks in the manufacturing process: power bottlenecks (PBN), where the replacement or upgrade of a machine would give the most considerable improvement in manufacturing line energy efficiency for the smallest cost, and downtime bottlenecks (DBN), where the replacement or upgrade of a machine would give the greatest reduction in downtime for the smallest cost. These analyses not only identify which parts of a system consume the most energy, but which are individually the most inefficient. This is an important distinction as although the overall process may be efficient compared with other means of manufacture, this does not conclude that all sub-systems are efficient. This is explored by Gutowski et al. [7], who used the example of a computer numerical control (CNC) machine to split energy requirements by sub-system, e.g., centrifuge, coolant, oil pressure pump, etc. This provides granularity on which specific sub-systems use the most energy and gives guidance on where to look for potential savings.

Sub-systems can have their energy categorised, an additional and essential level of detail, using the embodied product energy (EPE) model [13]. The EPE model categorises energy into direct energy (DE), the energy used by the manufacturing process, and indirect energy (IE), the energy used by the environment in which the process takes place. Direct energy is then further sub-divided into theoretical energy (TE), the minimum theoretical energy required for the actual desired process, and auxiliary energy ( $\mathrm{AE}$ ), the energy required by all the supporting equipment for the process. Using this model can enable the identification of inefficiencies at a more detailed level. When the energy breakdown 
of systems [7,14] are evaluated by this model, it becomes apparent that TE can often be a minority proportion, with $\mathrm{AE}$ and IE exceeding the TE for manufacturing processes. Using this model can enable the identification of inefficiencies at a more detailed level. The difference between the actual energy required for the process, TE, can be separated from all the supporting energy requirements. This can have the most significant effect when applied to the design phase of a system, as this is when the efficiency of a system is effectively locked in [15].

\subsection{Energy Modelling in Laser Systems}

The initial general categorisation, encompassing the device/unit to the facility level, of laser systems, was first carried out in the field of laser safety. The system itself could be broken down into three primary sections, with an additional fourth section ("People and Environment") covering its surroundings [16]. This categorisation format is still used and has been generalised to a wide variety of laser industries [17]. By using $\mathrm{O}^{\prime}$ Hagan's categories [16], all the separate equipment (sub-systems) required can be considered. Laser systems have a common set of energy and resource consuming sub-systems [18,19], which are shown in Table 1.

Table 1. Common laser sub-systems.

\begin{tabular}{cc}
\hline Category & Energy/Resource Consuming Sub-System \\
\hline Laser & Power supply \\
& Cooling system \\
& Laser consumables (e.g., gas) \\
Computers and control systems
\end{tabular}

A similar sub-system breakdown approach has been taken in certain specific laser processes. Paul and Anand [20] separated the energy-consuming sub-systems in selective laser sintering: laser, moving platforms, powder spreading, bed heating and miscellaneous energy. It has also been identified that these variables are not independent between the various sub-systems. Schmidt et al. [21] noted that laser selection would impact the relative size effect of power and cooling sub-systems.

Many prior studies of energy analysis of laser processing have focussed on the laser-material interaction itself, with little attention paid outside of this. Significant work on laser beam optimisation has already been carried out in a number of ways.

The use of ring-shaped beams was investigated by Wellburn et al. [22], who varied the relative intensities of the outside and centres of the beam for laser hardening, and Shang et al., who investigated different intensity profiles using a variable intensity modulator for laser cladding. Both of these works found a correlation between the beam profile and process zone uniformity. Wellburn et al. demonstrated the ability to control the uniformity of laser-hardened layers by modulating the outer and inner power ratios of a circular beam. Shang et al. found that biasing laser power to the outside of the ring gave a more uniform distribution of hard $\mathrm{Cr}$ and Fe dendritic phases through the volume of the clad track. 
Other beam types investigated include rectangular "top hat" beams by Mok et al. [23] and Riveiro et al. [24], and wedge-shaped beams by Bachmann [25]. Riveiro et al. specifically identified the laser source/chiller combination as a minority cost in the total cost of powder cladding (between $0 \%$ and $20 \%$ depending on the type of laser), with the main cost as the cost of the powder.

In addition to this, holographic optical elements, kinoforms which can be used to create customised laser beam profiles, have been studied by Kell et al. for laser welding [26], Higginson et al. for laser powder bed fusion (L-PBF) [27] and Goffin et al. for wire-fed laser cladding [28] and thin-film surface annealing [29]. The majority of these studies focused on metallurgical improvements, however, Goffin et al. also found that alterations in the beam profile allowed the creation of wire clad tracks with beam power requirements reduced by $30 \%$ for an enlarged gaussian beam and $50 \%$ for a square uniform beam.

Energy breakdown analyses have been completed in some laser applications. In power-bed laser additive manufacturing, Baumers et al. [30] defined a number of types of energy consumption analysis: where the energy can be measured according to the job, time, geometry or Z-height. Total energy was measured and then broken down into the build stages: warm up, build and cool-down time. Further work [31] ties this into cost model development for additive manufacturing (AM). A detailed energy breakdown of laser AM during the build itself was carried out by Paul and Anand [20], dividing the energy consumption into five components: $E_{L}$ (energy for running the laser system), $E_{p}$ (energy spent in moving the part and powder platforms), $E_{r}$ (energy spent to move the power spreading roller), $E_{b}$ (energy spent in heating the bed) and $E_{m}$ (miscellaneous energy). These features are common to all laser powder bed processes and this model can therefore be applied generically within this area. Moving beyond energy alone, Kellens et al. [32] utilised the UPCLI methodology to evaluate AM from an environmental impact perspective, utilising 17 categories. Of these, the largest impacts were to fossil depletion, climate change (both human health and ecosystem), particulate formation and human toxicity - with waste material and electricity being the primary contributors to these. This work allowed power bed AM users to quantify the environmental footprint of their systems.

In addition to laser AM, Kellens et al. carried out an energy breakdown of laser cutting processes [8]. This studied a number of different types of lasers, and broke the energy types down in a similar way to the EPE model. The laser cutting systems are broken down by sub-system, and energy use is traced through the cutting process. This is important for optimal energy savings to be made, as Duflou et al. [10] recognised.

There is a gap in the understanding of the detailed energy consumption of an entire laser system. Suitable frameworks and methodologies for categorising and analysing the energy of manufacturing processes have been identified, and so the specific aims of this paper are the following:

- To develop a categorisation strategy specific to the requirements of a laser system at each state in its operating cycle. This is to support the experimental analysis in this paper and to be used as a framework for future works;

- To conduct a power analysis on each element of the system architecture based on the EPE model to identify direct and indirect power draws of laser systems;

- To present recommendations to address the most significant sources of energy inefficiency for the future development of laser systems.

\section{Materials and Methods}

\subsection{The Categorisation of a Laser System}

A review of the existing literature has identified the need for a device/unit and line/cell levels analysis of a laser system. In this work, definitions of the identified laser system components were adapted from BSI 14955-1:2017, Annex C [33]. The standard focusses on the environmental evaluation of metal cutting machines; from this, a new set of definitions were developed to be laser-specific.

The system sub-components and associated terminology are defined as the following: 
Laser device: The device that produces the photons to be used for material processing. This also includes the device's power supply and any supply for any pump sources that are required. Where used, particularly if it is part of an integrated system, the laser device energy should include any requirements for pulsing, modulating, frequency manipulation, etc. Where it is possible to measure the supply of these latter components individually, these could be reported as separate requirements, but in general, should all fall under the heading of the laser device.

The energy requirements of the laser device itself should exclude the following sub-systems, which should all be analysed individually where possible:

Cooling system: Where applicable, this should include both the chiller/cooling mechanism and any associated pumps. It may be possible to separate the energy requirements of the cooling mechanism and a pump, but in general these should be grouped;

Extraction unit: This is the system in place for the removal of gases or ejected material from the workpiece. This should include any pumps, fans, scrubbing units (if active), etc. The energy used by the extraction system can include the embodied energy of the air removed from the room. This is not mandatory however, and should be clearly defined by setting the system boundary to either include it or not in any particular analysis;

Motion system: Any active systems for the manipulation of the beam, workpiece or laser delivery. Including actuators and drivers for these sub-systems. Also includes any sensors required for manipulation or process control (e.g., beam inspection system);

Control unit: Central power unit and computer control system;

Safety/interlock systems: Powered interlock system, warning lights and environmental monitoring.

The sub-systems listed so far are to be considered common to all laser processes. Each specific manufacturing process is then likely to have unique energy consumers:

Process-specific ancillaries which may be both auxiliary and theoretical consumers of energy. Process-specific ancillaries include sub-systems that are not common to all processes, e.g., the embodied energy of argon shielding gas for laser welding, or the energy for a heated bed in laser powder bed fusion [20]. This column would therefore be different for every process, and may even be absent in some cases. This group of sub-components would also have to include regulator/control devices for these processes.

Dependant on the level of analysis for a system, there are also consumers of energy beyond the cell level:

Indirect energies: Anything that is used to support the manufacturing environment, but that does not directly contribute to the manufacturing process. Examples might include, heating, ventilation, and air conditioning (HVAC), lighting and automated entry systems (e.g., security).

The standard (BSI 14955-1:2017) also requires the definition of operating modes, which can be used to contain the production modes at different life-cycle time points as identified by Kellens et al. [9]:

Off: All processing systems that are inactive and drawing no power;

Standby with peripheral units off: Control units and safety/interlocks are likely required to be operational first before the laser device, auxiliary units and process specific ancillaries are operational. Indirect energies will also be consuming;

Standby with peripheral units on: All sub-systems are on but in an idle or low-power state;

Warm-up: Request for all sub-systems to be active, but not warmed up. There may be a period when first turned on for sub-systems to become operational;

Ready for processing: All sub-systems active, with the system ready to operate but not yet in operation;

Processing: All sub-systems active, with the system in operation.

As with the original BSI 14855-1:2017, these operating modes are examples. Depending on the specific laser system, it is possible that some operating modes may not be relevant. It is also unclear in the generic layout what the exact sequence of events would be. However, this sequence will likely be significant to the overall energy consumption at non-processing modes. 


\subsection{Experimental Setup and Procedure}

For this investigation, an industrial standard laser welding system was used. Although based in a laboratory environment, each sub-system is an example commonly found in industry, making the overall system as close to the commercial standard as possible. The main deviation from a normal industrial system is the reduced level of integration between the various sub-systems which, fortuitously, allowed them to be more easily isolated and measured. The selection of a laser welding system is justified due to the commonality of laser welding to many high-value manufacturing industries, as well as its potential as a gateway into other manufacturing processes, such as directed energy deposition (DED) and additive manufacturing (AM).

In this research, a JK300FL (1070 nm) fibre laser (JK Lasers, Rugby, UK) with a maximum rated output of $300 \mathrm{~W}$ was used as the laser device around which a processing system was based. The fibre laser was coupled to a standard welding head and mounted about a 2-axis CNC system. This setup is shown in Figure 1.

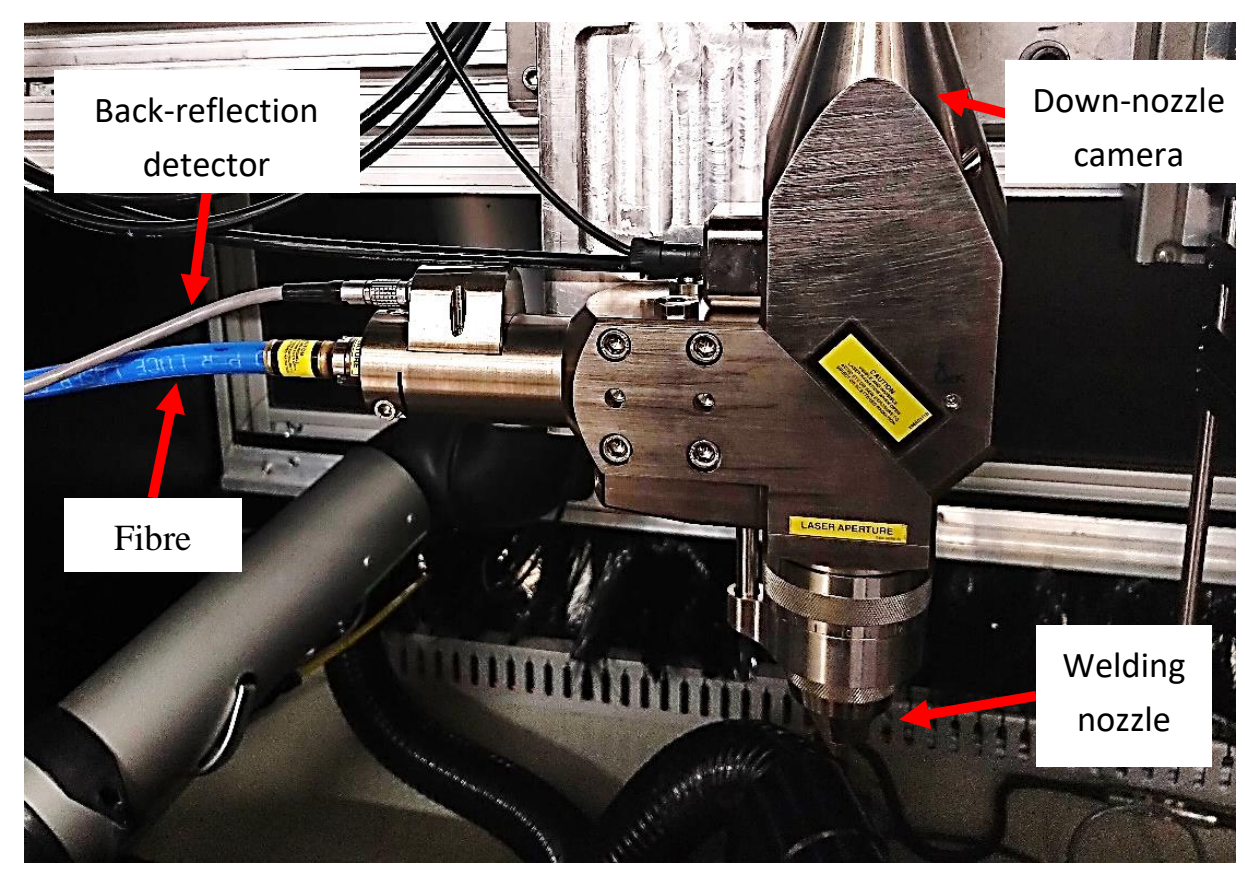

Figure 1. Laser welding head.

A laboratory-wide spinal extraction unit was used, with a sub-pipe to the laser welding system. The cooling system was an ICS Taeevo M03 chiller (Industrial Cooling Systems (ICS)), shared with an adjacent $1 \mathrm{~kW}$ fibre laser cell. The lasers were not used simultaneously in this study. This setup fulfilled two purposes. Firstly, the individual sub-systems used were as similar to industrial standard as possible, to make the results as industry-applicable as possible. Secondly, the system did not possess the level of integration that industrial laser systems typically possess. This made it easier to isolate and measure the sub-systems individually.

The electrical power measurement was conducted using a Cube 350 Ethernet System meter, packaged into a portable system and supplied by NewFound Energy. This is a 3-phase energy meter, with adaptors allowing single-phase metering for these trials. The system has its own web server and is controlled over a network by any connected computer via a web browser. It is capable of measurement rates of up to 1 data point per second, calculated from 1200 individual sub-samples per second, with a maximum current of $32 \mathrm{~A}$ and a maximum voltage of $230 \mathrm{~V}$ for single-phase $/ 400 \mathrm{~V}$ for 3-phase.

The energy meter can measure and record several different parameters, but for this study, three were of relevance. These are defined and summarised in Table 2. 
Table 2. Definition of electrical energy variables.

\begin{tabular}{ccc}
\hline Name & Units & Description \\
\hline Apparent power & $\mathrm{kVA}$ & $\begin{array}{c}\text { Direct multiplication of voltage and current, defined as kVA } \\
\text { rather than } \mathrm{kW} \text { in order to differentiate from the load, although } \\
\text { in direct current systems, the two are the same. This is the } \\
\text { electrical power drawn by the system. }\end{array}$ \\
\hline Load & $\mathrm{kW}$ & $\begin{array}{c}\text { The result of multiplying the apparent power and power factor. } \\
\text { This is the electrical power actually used by the system, allowing } \\
\text { for inefficiencies due to inductive or capacitive phase shifts. }\end{array}$ \\
\hline Power factor & Non-dimensional & $\begin{array}{r}\text { The ratio between apparent power and load. Analogous to } \\
\text { efficiency in mechanical systems. }\end{array}$ \\
\hline
\end{tabular}

The device was specified as Class 0.25 for the $\mathrm{kW}$ and $\mathrm{kVA}$ measurements according to BS EN 60688:2013, giving an accuracy of $\pm 0.25 \%$ at the fiducial value (32 A). Multiple investigative stages were required in order to capture sufficient information about individual energy consumers in the laser processing system. This was due to several pieces of equipment being powered by the same supply and the need to understand consumption across various operational parameters.

The laser beam output power was characterised by the use of a Coherent LM-200 air-cooled power meter (Coherent, Ely, UK). This allowed a correlation to be created between the percentage power setting defined in the control software and the laser beam emerging from the welding head. This accounted for all losses through the optics. The correlation is shown in Figure 2, giving a linear relationship, based on three readings per data point with standard deviations less than $0.5 \mathrm{~W}$-too small to be relevant. The trendline formula allowed the required power setting to be calculated for any required output power. The maximum applied laser beam power was found to be $250 \mathrm{~W}$ at the $100 \%$ power setting, $50 \mathrm{~W}$ lower than the rated $300 \mathrm{~W}$ maximum.

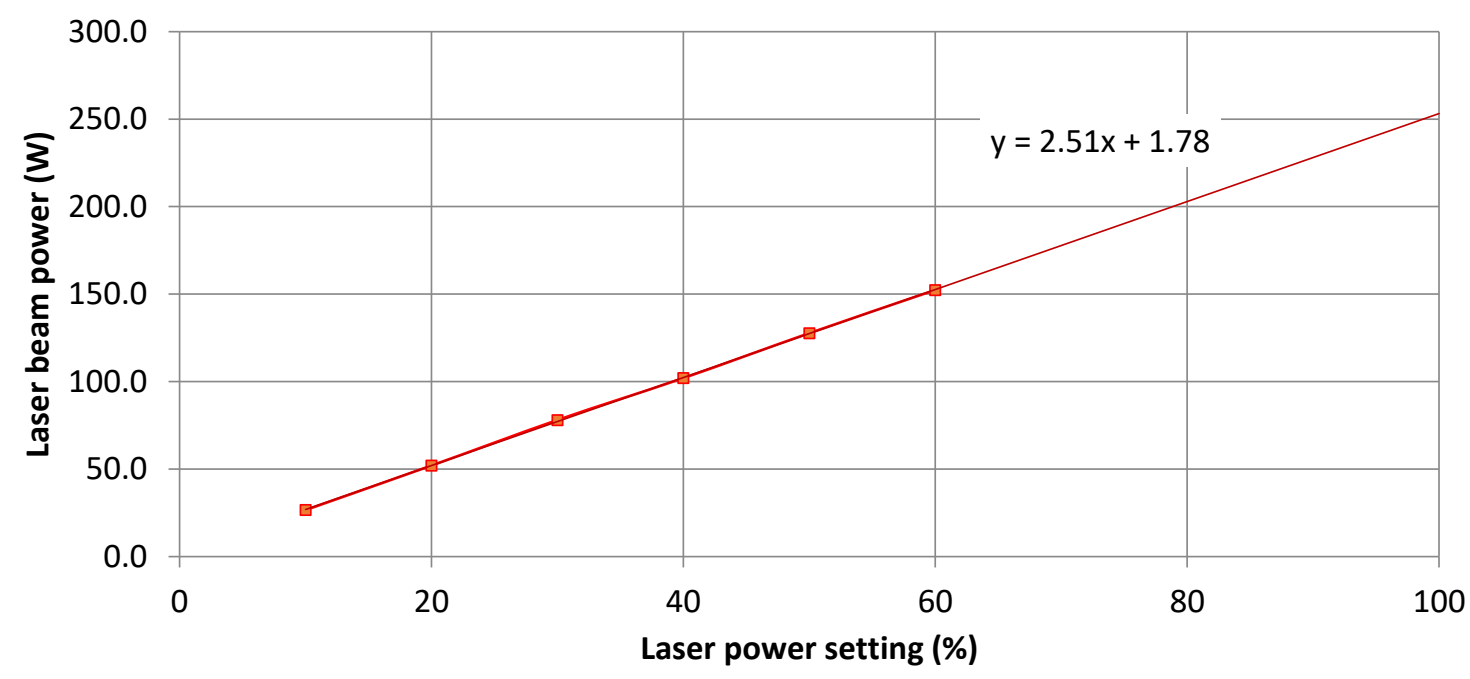

Figure 2. Correlation of laser power setting vs. beam power.

Energy monitoring was carried out at the device/unit and line/cell levels, according to Duflou's hierarchy, with the investigation covering both the laser cell as a whole and the sub-units within it. As discussed above, definitions of the laser system components were adapted from BSI 14955-1:2017, Annex C [33], representing a combined approach, utilising the system sub-components in conjunction with Gutowski et al.'s method of energy monitoring.:

- Operating states were defined as "Off", "Standby with peripheral units off", "Standby with peripheral units on", "Warm Up", "Ready for processing" and "Processing";

- Sub-systems were defined as "Laser", "Extraction", "Cooling", "Motion" and "Control". 
At this stage in the energy investigation, the "Process-specific ancillaries" column was disregarded. This meant that the embodied energy from the compressed gas argon shield was ignored, as were the effects from gas cooling on laser power for material processing. These are intended to be considered at a later research stage where a particular process is investigated. The control unit, safety interlock systems and indirect energies were grouped together in the "Control" column. In addition, "Standby with peripheral units off" and "Warm up" were disregarded since they do not apply to this system, giving the reduced number of operating states shown in Table 3. Each of the sub-systems in this table was isolated and then measured in its relevant operating states.

Table 3. Specific operating states investigated.

\begin{tabular}{cccccc}
\hline & Laser & Extraction & Cooling & Motion & Control \\
\hline Off & OFF & OFF & OFF & OFF & OFF \\
Standby with peripheral units on & OFF & OFF & ON & OFF & ON \\
Ready for processing & ON & ON & ON & OFF & ON \\
Processing & ON & ON & ON & ON & ON \\
\hline
\end{tabular}

\section{Results}

\subsection{Characterisation of Laser Power}

The laser energy draw was tested at power settings between $40 \%$ and $100 \%$ at $10 \%$ intervals. This corresponded to the beam output powers between 102 and $253 \mathrm{~W}$, as shown in Figure 3. Each reading is given as a mean of between 6 and 10 individual data points, with error bars displayed at one standard deviation.

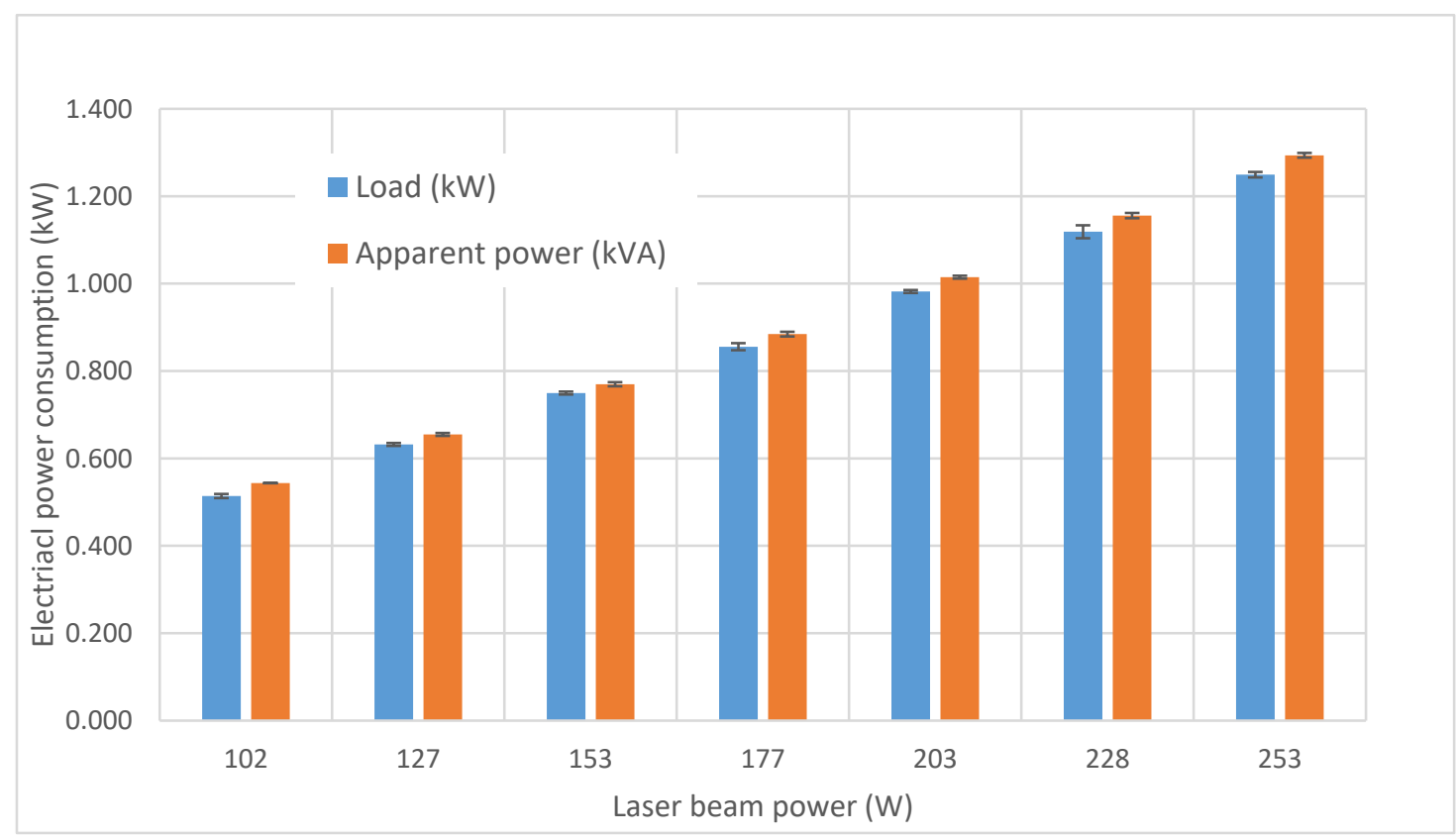

Figure 3. Laser beam power vs. Electrical power consumption.

The similar recordings of load and apparent power show that the laser has a very high power factor (average 0.965, standard deviation 0.008) and thus very high electrical efficiency. This is as expected since it is a solid-state system with no moving parts. A linear relationship is evident between laser beam power and laser electrical power, with the narrow error bars showing the stability of the laser output. Its beam generation (pump) efficiency is much lower, however, at an average of a $20.3 \%$ 
(standard deviation $0.2 \%$ ) ratio between the beam output power and the electrical power consumption. This represents the typical performance for fibre lasers of this generation.

\subsection{Characterisation of Extraction Unit Power}

In this system, the extraction unit was exceptional in that it was simply either "ON" or "OFF". A single system was also used to extract for the entire laboratory, which contained a diversity of different laser systems. It was therefore vastly larger and more powerful than would have been required for the welding system only.

Since there was no capability to isolate the extraction for the welding system, an estimate was made by measuring the power draw of the overall extraction system and then using the cross-sectional areas and flow rates of the pipes to estimate the percentage of overall flow allocated to the welding system, given in Table 4. A direct relationship was assumed between the air flow ratio and the power draw, such that the same ratio was used to allocate a proportion of the overall energy use to the laser system. Direct current and voltage measurements are shown in Table 5.

Table 4. Flow rate ratio calculations.

\begin{tabular}{ccccc}
\hline & $\begin{array}{c}\text { Measured Flow } \\
\text { Rate }(\mathbf{m} / \mathbf{s})\end{array}$ & $\begin{array}{c}\text { Pipe Cross-Sectional } \\
\text { Area }\left(\mathbf{m}^{\mathbf{2}}\right)\end{array}$ & $\begin{array}{c}\text { Volume Flow Rate } \\
\left(\mathbf{m}^{\mathbf{3}} \mathbf{/ s}\right)\end{array}$ & Flow Rate Ratio \\
\hline Main extraction pipe & 9.6 & 0.049 & 0.471 & 0.11 \\
\hline 300 W fibre laser system & 2.92 & 0.018 & 0.052 & 0.11 \\
\hline
\end{tabular}

Table 5. Extraction current and voltage measurements.

\begin{tabular}{ccccc}
\hline & Phase 1 & Phase 2 & Phase 3 & Mean \\
\hline Current (A) & 3.28 & 3.64 & 3.22 & 3.38 \\
& Phase 1-2 & Phase 1-3 & Phase 2-3 & Mean \\
3-phase voltage (V) & 416 & 416 & 414 & 415.33 \\
\hline
\end{tabular}

These measurements were used to find the power levels in Table 6, with the flow rate ratio used to calculate how much of the laboratory-wide extraction was being used by the laser specifically. This was because in this specific laboratory, the extraction unit was a constant draw system; there was no ability to scale the laboratory-wide extraction power proportionally with the demand when just this laser system was operating.

Table 6. Extraction power calculations.

\begin{tabular}{ccc}
\hline & Laboratory-Wide Extraction Power & Cell-Specific Extraction Power \\
\hline Power factor & 0.85 & 0.85 \\
Apparent power $(\mathrm{kVA})$ & 2.43 & 0.267 \\
Load $(\mathrm{kW})$ & 2.07 & 0.228 \\
\hline
\end{tabular}

For the purposes of this investigation, the cell-specific power draws were used, since the laboratory-wide figures are unique to a specific location and do not apply broadly. They still have relevance, however. Modern extraction systems are fully capable of a scaled output, but many older ones, such as the one used here, are not. If older systems are still in use in a laboratory or workshop, it is worth investigating the benefits of upgrades; Table 6 shows that in this case, an approximately $89 \%$ power saving is possible.

\subsection{Characterisation of Cooling System Power}

In order to characterise the chiller system power draw, the laser system was run continuously for $15 \mathrm{~min}$, at varying power levels, with the CNC motion system on a continuous loop in order to avoid overheating a single location. 
With the chiller off, it drew no power at all. With the chiller on, it would continuously circulate the coolant through the system, with a noticeable power draw from the pump. When the laser temperature became excessive, the chiller would then start cooling, until it reduced the temperature to an acceptable level. There were, therefore, two distinct power draw levels in the chiller performance: "pump only" and "pump + chiller", shown in Figure 4.

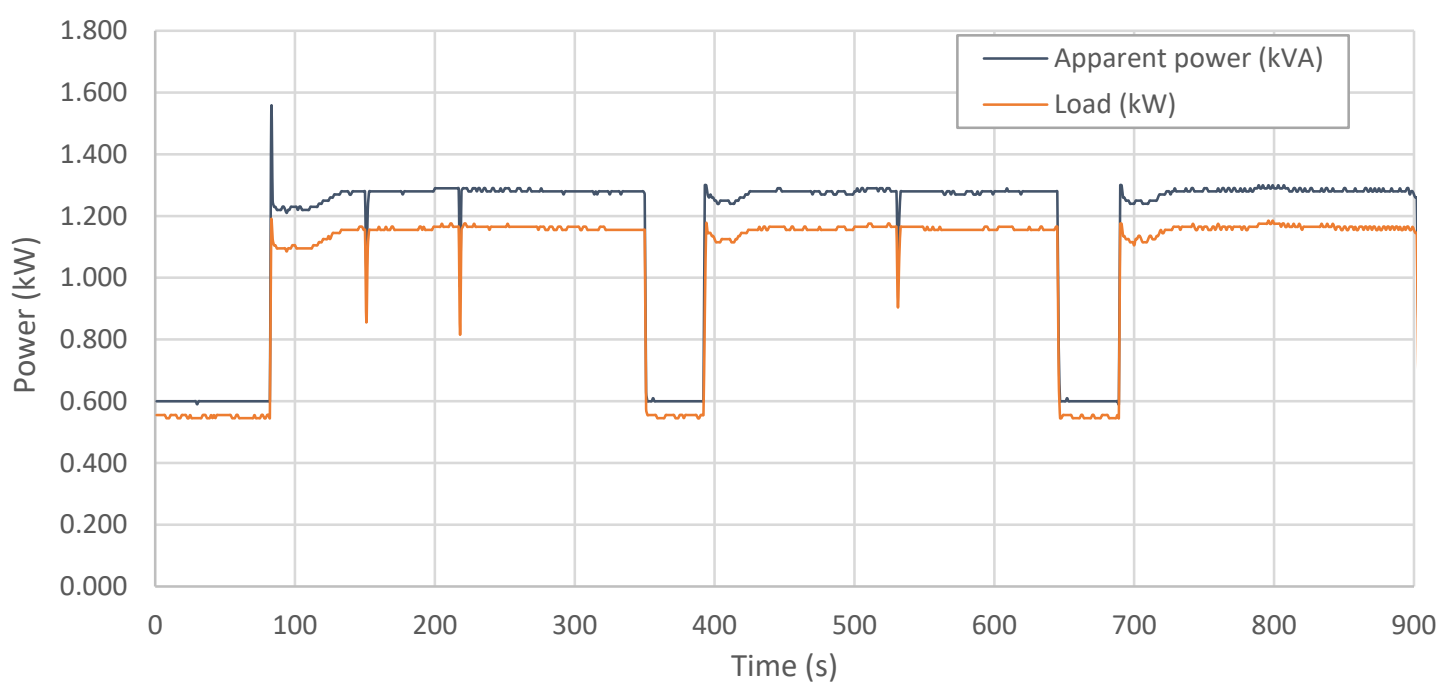

Figure 4. Total cooling system load levels for laser running at $120 \mathrm{~W}$.

The power draw for the cooling system was predictable, with both the pumping only and active cooling modes drawing the same amount of power regardless of the power of the laser. This is shown in Table 7, for both the kVA and kW measurements. In all cases, the pumping accounted for just under half $(46-48 \%)$ of the total power draw when the chiller was active, with the cooling accounting for the remainder, but only when it was active.

Table 7. Chiller power measurements at different laser power levels.

\begin{tabular}{|c|c|c|c|c|c|c|}
\hline Laser Power & $\begin{array}{l}\text { Overall Chiller } \\
\text { Power, kVA }\end{array}$ & $\begin{array}{c}\text { Chiller } \\
\text { Pumping, kVA }\end{array}$ & $\begin{array}{c}\text { Chiller Cooling, } \\
\text { kVA }\end{array}$ & $\begin{array}{l}\text { Overall Chiller } \\
\text { Load, kW }\end{array}$ & $\begin{array}{c}\text { Chiller } \\
\text { Pumping, kW }\end{array}$ & $\begin{array}{c}\text { Chiller Cooling, } \\
\text { kW }\end{array}$ \\
\hline \multirow{2}{*}{$80 \mathrm{~W}$ test } & \multirow{2}{*}{1.293125} & 0.601 & 0.693 & \multirow{2}{*}{1.163125} & 0.55 & 0.611 \\
\hline & & $46 \%$ & $54 \%$ & & $47 \%$ & $53 \%$ \\
\hline \multirow{2}{*}{$120 \mathrm{~W}$ test } & \multirow{2}{*}{1.279375} & 0.600 & 0.679 & \multirow{2}{*}{1.16} & 0.551 & 0.609 \\
\hline & & $47 \%$ & $53 \%$ & & $47 \%$ & $53 \%$ \\
\hline $160 \mathrm{~W}$ test & 1.266875 & 0.606 & 0.661 & 1.14875 & 0.553 & 0.596 \\
\hline \multirow{2}{*}{$200 \mathrm{~W}$ test } & \multirow{2}{*}{1.265} & 0.601 & 0.664 & \multirow{2}{*}{1.169375} & 0.558 & 0.611 \\
\hline & & $47 \%$ & $53 \%$ & & $48 \%$ & $52 \%$ \\
\hline \multirow{2}{*}{$240 \mathrm{~W}$ test } & \multirow{2}{*}{1.25125} & 0.595 & 0.656 & \multirow{2}{*}{1.169375} & 0.55 & 0.619 \\
\hline & & $48 \%$ & $52 \%$ & & $47 \%$ & $53 \%$ \\
\hline
\end{tabular}

The chiller modulated its cooling effect by monitoring the coolant temperature and then adjusting the amount of active cooling in order to extract the correct amount of heat. The power draw of the cooling system was controlled by increasing the proportion of the duty cycle devoted to active cooling, as opposed to its power level. As the laser power increased, the proportion of time that the cooling system was actively cooling also increased, up to a point where it was active continuously for the duration of the time measured.

\subsection{Characterisation of Motion System Power}

The CNC system was tested at a variety of speeds and payloads. These parameters are given in Table 8 . The base load describes the CNC system with only the base mounted and loads of increasing 
mass added. Five loads and eight different speeds were tested, with each load being tested at every speed, giving 40 tests in total.

Table 8. CNC testing parameters.

\begin{tabular}{cc}
\hline Payload Weights (kg) & Motion Speeds $(\mathbf{m m} / \mathbf{s})$ \\
\hline Base load & 5 \\
Base load $+2 \mathrm{~kg}$ & 10 \\
Base load $+4 \mathrm{~kg}$ & 15 \\
Base load $+6 \mathrm{~kg}$ & 20 \\
Base load $+8 \mathrm{~kg}$ & 25 \\
& 30 \\
& 35 \\
& 40 \\
\hline
\end{tabular}

Figure 5 shows the plots of power draw vs. time for all payloads. Power draws were all extremely similar, with a mean power factor of 0.743 .

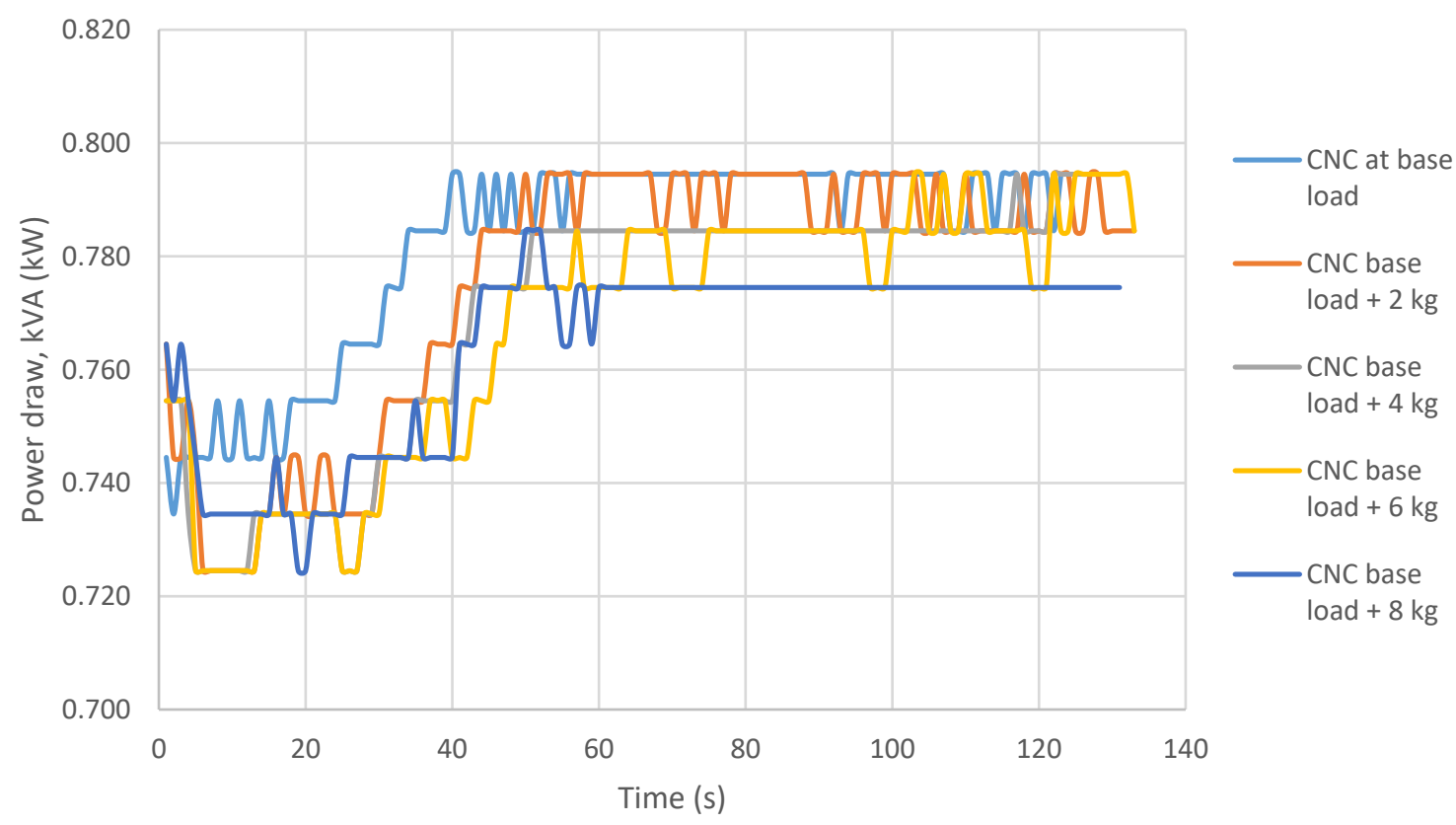

Figure 5. Power draw vs. speed for all CNC payloads.

The CNC power draw stayed almost constant at all parameters. The reason for this is due to the stepper motor-based drive system, which does adjust according to the load or speed. The system will always draw the same amount of power until a maximum limit for the load or speed is reached, at which point it will no longer function. The CNC system is relatively electrically inefficient, with power factors around 0.75 .

\subsection{Characterisation of Control Unit Power}

Firstly, the power demand for each sub-system was characterised in their idle state. This is where they were active and switched on, but not actually processing, e.g., the laser was on but not emitting a laser beam. The power measurements for these are given in Table 9.

The support system power draws were universally very low, especially since the meter's accuracy was specified at $\pm 0.25 \%$. Of these four measurements, the cabinet electrics and laser control were both above $1 \%$ of the fiduciary value, and so could be considered to be reasonably reliable. This gives $0.39 \mathrm{~A}$ and $0.09 \mathrm{~kW}(\mathrm{kVA})$ as the reasonable minima for the power measurement. 
Table 9. Power draws for active but idle systems.

\begin{tabular}{cccc}
\hline System Sub-Component & Current Draw (A) & Power Draw (kW) & Power Draw (kVA) \\
\hline Cabinet electrics & 0.39 & 0.04 & 0.09 \\
CNC control & 0.005 & 0.024 & 0.000 \\
Laser control & 1.18 & 0.256 & 0.280 \\
PC & -0.003 & -0.003 & 0.001 \\
\hline
\end{tabular}

The CNC control and personal computer (PC) readings were both below the accuracy range of the meter and were therefore assumed to be unreliable. On the basis of the other measurements, it was estimated that the correct power draw for them is between 0 and $0.09 \mathrm{~kW}(\mathrm{kVA})$. For the purposes of further analysis, they were treated as each drawing $0.09 \mathrm{~kW}(\mathrm{kVA})$, with the caveat that this represents an upper limit.

\section{Analysis and Discussion}

As a result of the power characterisation of the laser's sub-systems, it is possible to create overall power maps of the laser welding system, as shown in Figure 6. Two such maps are presented, with the laser power at $120 \mathrm{~W}$ and $240 \mathrm{~W}$, respectively.

The energy requirements of the various sub-systems for the laser processing system were assessed individually, in a similar way to that described by Gutowski et al. [7]. In order to evaluate the usefulness of the energy users, it is possible to apply a similar energy modelling approach to that described by Seow and Rahimifard [13]. However, in their approach, the model is designed specifically for discrete manufacturing in order to reduce the embodied product energy of products. In this current work, the focus is on the energy used by a "generic" laser processing system, in which case there is no specific product that energy can be attributed to. Instead it is more appropriate to consider the power drawn by a system and its sub-components which makes more sense if you are seeking to compare the energy efficiency of similar processes. In this analysis, the following definitions for power draw were used:

- Auxiliary power (AP): The sum of the all the power inputs which supported the process but do not directly cause melting. This represents a category where energy savings are possible within the bounds of the existing relevant sub-systems. The power categorised here consists of those elements considered necessary for the process to proceed (e.g., CNC motion, cooling, etc.), but which do not contribute directly to the laser-material interaction;

- Processing power (PP): A process-specific modification of the concept of direct energy (DE) [13], the sum of all power inputs that contributed directly to the beam-material interaction process. In this case, it was solely the laser beam, but it is possible to imagine a scenario that uses an electron beam or plasma/arc torch instead, or some hybrid combination of the processes. PP includes theoretical power (TP), which is the minimum amount of laser beam energy required to actually melt/process a given volume of material at a given rate, and reflected power (RP), which represents the energy that is emitted but lost to reflection (and other loses such as the proportion of beam emitted through the bottom of the Kerf in cutting, or the energy used to create a heat affected zone). $\mathrm{RP}$ is similar to $\mathrm{AP}$, in that its presence is essentially required to allow processing to take place but it makes no direct contribution. It is categorised differently in order to distinguish between this type of energy loss and the energy required to support the sub-systems;

- Electrical supply waste (ESW): This category incorporates the sum of all the electrical losses in the system, based on the power factor. This energy provides no benefit and efficiency improvements here require the redesign or replacement of the relevant sub-systems to improve their power factors (work which was outside the scope of this investigation).

This combination of approaches and definitions of power components allowed the simultaneous mapping of energy draws by sub-systems and the categorisation of these draws by function, giving a complete analysis of laser processing energy flows at a system level. This showed that 
at $120 \mathrm{~W}$ laser power, only a tiny proportion of the power required by the system (3.45\%) is attributed to processing power, with the remainder being used by the auxiliary systems $(72.2 \%)$ or lost as supply waste $(24.3 \%)$. When the laser is running close to the maximum at $240 \mathrm{~W}$, these percentages change to $6.00 \%, 63.1 \%$ and $30.9 \%$, respectively. When running the laser at a high power, the system electrical efficiency is increased because all other system power draws remain constant. The higher power setting also generates more waste heat, so the supply waste percentage is also increased, which explains why the auxiliary system percentage reduces. In this study, the power requirements by indirect energy consumers were not considered, although these will always lead to lower effective system efficiencies. The implication is that for energy efficiency improvements in laser processing systems, efforts should not primarily be focused towards developing more efficient laser devices, but towards better designed auxiliary systems and an improved consideration for the matching of sub-components.

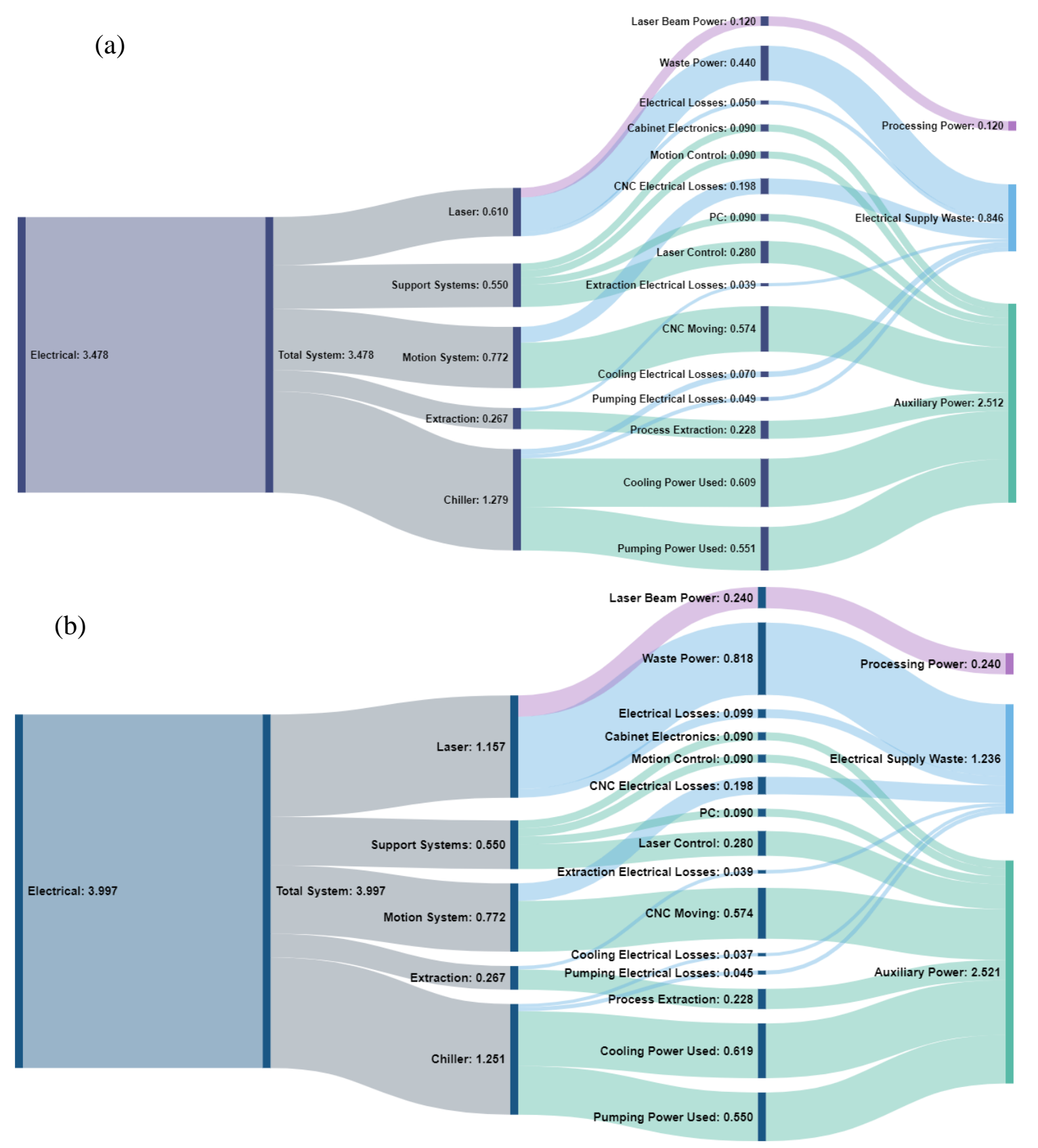

Figure 6. Laser welding power flows (kVA), (a) with the laser beam power at $120 \mathrm{~W}$ and (b) with the laser beam power at $240 \mathrm{~W}$. 
A large percentage of the energy draw was lost as electrical supply waste: an issue with load balancing due to the fundamental design of the individual components of the system. These losses could be reduced through the implementation of load balancing devices or through the use of better-designed equipment. However, this does serve to corroborate the results found by Seow et al. [15], that a large proportion of energy cost is "locked in" at the design phase. There is no way of reducing these energy losses without using different equipment because these energy losses are fundamental to how the equipment is designed.

The vast majority of power consumption at both power levels was found to lie in the auxiliary power rather than in the processing power. For the support system measurements, the power measurements were of the order of the lowest possible resolution of the energy meter. The current draw for the CNC control and PC were too low to be reliably measured by the power meter (accurate to approximately $\pm 1 \%$ of $32 \mathrm{~A}$ ). For this reason, power factors were also ignored, since they were impossible to quantify accurately, and the resulting waste energy would be too small to make any real difference. The measurement of the cabinet electrics at $0.39 \mathrm{~A}$ appeared to be the minimum possible accurate measurement, translating to $0.09 \mathrm{~kW}$. The CNC control and PC current draws were therefore somewhere between 0 and $0.09 \mathrm{~kW}$. For the purposes of power mapping, the worst case was assumed, and these were treated as if they were running at $0.09 \mathrm{~kW}$, in the knowledge that they would be no higher than that.

The cooling system was the single largest draw, but its power profile was somewhat complex. It was split into cooling and pumping branches, with the cooling branch only active when the coolant reservoir temperature went above a certain setpoint. The specific cooling system used here was designed to cool both a $300 \mathrm{~W}$ and $1000 \mathrm{~W}$ laser system simultaneously and was therefore too powerful for its role in cooling only the laser system in use. Since a smaller cooling system would surely save energy in this specific laboratory setup, the implication is that there are opportunities to better match cooling systems to specific laser processing systems, but with a consideration for future-proofing if ever the laser needs to be upgraded. In this study, the cooling system power draws did not change when the laser beam power was increased. However, when a specific welding process is investigated and the total process energy is measured rather than the power draw, the time-based nature of the cooling system operation would be captured. It would be expected to use more energy at higher laser beam power levels, even though, as has been seen here, the maximum power draw would not be expected to vary proportionally with the laser beam power.

In the final analysis of extraction, the overall power draw was excluded and only that used by the laser system was considered. In this specific instance, the extraction system was not scalable (it ran at a set power), so the entire $2.4 \mathrm{~kW}$ was required to be active. However, this is a characteristic specific to the hardware used in this investigation. Again, the implication is that there is a significant advantage to specifying extraction systems for individual processes and also having the ability to dynamically control the system such that extraction is only performed when needed.

Further to this, a potential way to improve extraction energy efficiency would come in the form of improvements to the design of extraction nozzles within the specific laser system itself, which would reduce the power requirements regardless of the specific type of pump used. Work has been carried out by Lobo et al. [34], characterising the relationship between the fume generation and process parameters in laser cutting. There is, therefore, potential to optimise the flow of extraction, such to meet the requirements for welding fume extraction as defined by the UK Health and Safety Execute (HSE), but with minimised pumping power.

The application of the metering process and subsequent analysis allows the evaluation of the power required by different energy users within the system. Importantly, it allows the quick identification of the largest energy consumers and consideration as to where energy efficiency improvements could be made. The hardware required for this process, although bespoke to this research, is commonly available to industry, and did not require any invasive hardwiring. The procedure is, therefore, suitable for implementation by facility/energy managers within industrial environments. 
These results allow energy-saving strategies to be effectively targeted at the most energy-intensive sub-systems, with the potential for significant reductions in carbon footprint.

\section{Conclusions}

The following outputs have been generated from this work:

- Laser systems can be energy modelled in the same way as other manufacturing systems. Existing manufacturing energy frameworks have been adapted for laser materials processing. In this study, the sub-components of the laser system were broken down in a similar way to Gutowski et al. [7], with energy categorised according to a modified version of the manufacturing energy model created by Seow and Rahimifard [13];

- The overall power draw of a laser welding system has been characterised and broken down by sub-system. Areas have been identified where energy savings can be made, and others have been discounted from further exploration;

- The power draw of the laser itself represents only a minority proportion of the overall system power draw. At the power levels studied, the laser drew just $17.5 \%$ of the overall power, with only $3.45 \%$ being the laser beam itself. This puts the improvements in the laser-material interaction, such as those found by Goffin et al. [28], in perspective. While energy savings in laser beam power can be a large fraction of the beam power, this still only represents a very small percentage of the overall system power. Previously unexplored potential exists to make savings in auxiliary systems, with greater impact on the overall system power;

- When the laser power is increased, the proportion of overall power drawn by the laser system also increases. At a $240 \mathrm{~W}$ beam power, the laser system drew $28.9 \%$ of the total system power, of which $6 \%$ was the laser beam, representing a significant increase from a $120 \mathrm{~W}$ laser beam power. This is because many of the auxiliary system power requirements are not directly influenced by the laser itself and do not alter with the changes in the laser power. This means that a higher power setting is more electrically efficient, for a given set of sub-systems;

- A significant level of power is drawn by the cooling system. Although it has a very stable power draw in both the pumping and cooling modes, the large difference in power between these modes and the fact that it switches between them during the process makes the overall energy usage difficult to evaluate. More investigation is required to better characterise this pattern and identify if there are any opportunities for efficiency improvements.

As a result of this, some areas have been identified for further development with others discounted;

- While the extraction pumping system itself is out of bounds for an investigation opportunity, it has been identified for better optimisation in the design of the extraction nozzle to reduce the overall volume of air that needs to be evacuated in order to meet HSE requirements. This would give a more effective extraction system for the same power draw, or a smaller power draw for equal effectiveness, allowing energy savings regardless of the specific type of extraction system;

- Making the laser itself more efficient is out of scope, but it is possible that further investigation into welding optimisation would allow a reduction in the laser beam power. Given that the laser system efficiency is a fixed ratio, a reduction in direct energy would yield a proportional reduction in indirect energy, regardless of the specific laser system in use. In a similar way to that noted by Schmidt et al. [21] for individual sub-components, there is cross-talk between different energy categories within the same sub-component as well;

- A more sophisticated analysis of the CNC power draw is required. Differences between axis loading in $\mathrm{x}$ and $\mathrm{y}$ have yet to be addressed;

- A time-based analysis of the cooling system, after the fashion of Kellens et al. [9], is required to enable the relative shares of pumping and cooling used for any particular process. At present, just the power draw was recorded, but this further analysis will allow the power readings to be converted to energy readings; 
- The work completed here was carried on a system designed to be as close to a normal industrial system as possible, such that the results are relevant to industry. However, since this work was carried out in a laboratory environment, further work is needed in industrial environments to better verify the results obtained here. Such work would also allow the identification of areas where the existing methodology needs to be refined to account for the differences between a laboratory study and industrial processes.

Author Contributions: Conceptualization, E.W., N.G., L.C.R.J. and J.T.; methodology, N.G. and E.W.; formal analysis, N.G.; investigation, N.G.; data curation, N.G.; writing-original draft preparation, N.G. and E.W.; writing-review and editing, N.G., E.W., L.C.R.J., J.T., J.O. and P.M.; visualization, N.G.; supervision, E.W.; project administration, E.W. and P.M.; funding acquisition, P.M., E.W. L.C.R.J. and J.T. All authors have read and agreed to the published version of the manuscript.

Funding: This research was funded by the EPSRC, grant number EP/S018190/1.

Acknowledgments: The authors wish to thank Mark Capers and Dave Britton for their helpful technical support.

Conflicts of Interest: The authors declare no conflict of interest.

\section{References}

1. Griffin, P.W.; Hammond, G.P.; Norman, J.B. Industrial energy use and carbon emissions reduction: A UK perspective. Wiley Interdiscip. Rev. Energy Environ. 2016, 5, 684-714. [CrossRef]

2. UK Department for Business Energy and Industrial Strategy. The Climate Change Act. 2008 (2050 Target. Amendment) Order 2019; UK Government: London, UK, 2019.

3. Energy Balance Sheets 2009-2010. Available online: https://ec.europa.eu/eurostat/documents/3217494/5747681/ KS-EN-12-001-EN.PDF/4d084c96-c54a-4149-aed3-e24ae09401a2 (accessed on 19 May 2020).

4. United States Environmental Protection Agency. Draft Inventory of U.S. Greenhouse Gas. Emissions and Sinks: 1990-2018; EPA: Washington, DC, USA, 2020.

5. Dyer, C.H.; Hammond, G.P.; Jones, C.I.; McKenna, R.C. Enabling technologies for industrial energy demand management. Energy Policy 2008, 36, 4434-4443. [CrossRef]

6. Duley, W.W. Laser Welding; John Wiley \& Sons Ltd: New York, NY, USA, 1999.

7. Gutowski, T.; Dahmus, J.; Thiriez, A. Electrical Energy Requirements for Manufacturing Processes. In Proceedings of the 13th CIRP International Conference of Life Cycle Engineering, Lueven, Belgium, 31 May-2 June 2006; pp. 623-628.

8. Kellens, K.; Rodrigues, G.C.; Dewulf, W.; Duflou, J.R. Energy and resource efficiency of laser cutting processes. Phys. Procedia 2014, 56, 854-864. [CrossRef]

9. Kellens, K.; Dewulf, W.; Overcash, M.; Hauschild, M.Z.; Duflou, J.R. Methodology for systematic analysis and improvement of manufacturing unit process life-cycle inventory (UPLCI)-CO2PE! initiative (cooperative effort on process emissions in manufacturing). Part 1: Methodology description. Int. J. Life Cycle Assess. 2012, 17, 69-78. [CrossRef]

10. Duflou, J.R.; Sutherland, J.W.; Dornfeld, D.; Herrmann, C.; Jeswiet, J.; Kara, S.; Hauschild, M.; Kellens, K. Towards energy and resource efficient manufacturing: A processes and systems approach. Cirp Ann. Manuf. Technol. 2012, 61, 587-609. [CrossRef]

11. Rodrigues, G.S.; Ferreira, J.C.E.; Rocha, C.R. A novel method for analysis and optimization of electric energy consumption in manufacturing processes. Procedia Manuf. 2018, 17, 1073-1081. [CrossRef]

12. Bajpai, A.; Fernandes, K.J.; Tiwari, M.K. Modeling, analysis, and improvement of integrated productivity and energy consumption in a serial manufacturing system. J. Clean. Prod. 2018, 199, 296-304. [CrossRef]

13. Seow, Y.; Rahimifard, S. A framework for modelling energy consumption within manufacturing systems. Cirp J. Manuf. Sci. Technol. 2011, 4, 258-264. [CrossRef]

14. Rahimifard, S.; Seow, Y.; Childs, T. Minimising embodied product energy to support energy efficient manufacturing. Cirp Ann. Manuf. Technol. 2010, 59, 25-28. [CrossRef]

15. Seow, Y.; Goffin, N.; Rahimifard, S.; Woolley, E. A ‘Design for Energy Minimization' approach to reduce energy consumption during the manufacturing phase. Energy 2016, 109, 894-905. [CrossRef]

16. O'Hagan, J.B. Safety Aspects of Laser Displays. Radiat. Prot. Dosim. 1997, 72, 241-248. [CrossRef]

17. Barat, K. Laser Safety Management; Taylor \& Francis: Boca Raton, FL, USA, 2017. 
18. Penchev, P.; Dimov, S.; Bhaduri, D.; Soo, S.L. Generic integration tools for reconfigurable laser micromachining systems. J. Manuf. Syst. 2016, 38, 27-45. [CrossRef]

19. Ready, J.F.; Farson, D.F. (Eds.) LIA Handbook of Laser Materials Processing Contents; LIA \& Magnolia Publishing: Orlando, FL, USA, 2001.

20. Paul, R.; Anand, S. Process energy analysis and optimization in selective laser sintering. J. Manuf. Syst. 2012, 31, 429-437. [CrossRef]

21. Schmidt, M.; Zäh, M.; Li, L.; Duflou, J.; Overmeyer, L.; Vollertsen, F. Advances in macro-scale laser processing. Cirp Ann. 2018, 67, 719-742. [CrossRef]

22. Wellburn, D.; Shang, S.; Wang, S.Y.; Sun, Y.Z.; Cheng, J.; Liang, J.; Liu, C.S. Variable beam intensity profile shaping for layer uniformity control in laser hardening applications. Int. J. Heat Mass Transf. 2014, 79, 189-200. [CrossRef]

23. Mok, S.H.; Bi, G.; Folkes, J.; Pashby, I. Deposition of Ti-6Al-4V using a high power diode laser and wire, Part I: Investigation on the process characteristics. Surf. Coat. Technol. 2008, 202, 3933-3939. [CrossRef]

24. Riveiro, A.; Mejías, A.; Lusquiños, F.; Del Val, J.; Comesaña, R.; Pardo, J.; Pou, J. Laser cladding of aluminium on AISI 304 stainless steel with high-power diode lasers. Surf. Coat. Technol. 2014, 253, 214-220. [CrossRef]

25. Bachmann, F. Industrial applications of high power diode lasers in materials processing. Appl. Surf. Sci. 2003, 208, 125-136. [CrossRef]

26. Kell, J.; Tyrer, J.R.; Higginson, R.L.; Jones, J.C.; Noden, S. Laser weld pool management through diffractive holographic optics. Mater. Sci. Technol. 2011, 28. [CrossRef]

27. Higginson, R.L.; Blackmur, M.; Gibson, M.; Tyrer, J. Grain Size Control in the Weld Pool and Heat Affected Zone Using Holograms. Mater. Sci. Forum 2012, 715-716, 340-345. [CrossRef]

28. Goffin, N.J.; Higginson, R.L.; Tyrer, J.R. The use of Holographic Optical Elements (HOE's) to investigate the use of a flat irradiance profile in the control of heat absorption in wire-fed laser cladding. J. Mater. Process. Technol. 2015. [CrossRef]

29. Goffin, N.; Tyrer, J.; Woolley, E. Complex beam profiles for laser annealing of thin-film CdTe photovoltaics. J. Laser Appl. 2018, 30, 042006. [CrossRef]

30. Baumers, M.; Tuck, C.; Bourell, D.L.; Sreenivasan, R.; Hague, R. Sustainability of additive manufacturing: Measuring the energy consumption of the laser sintering process. Proc. Inst. Mech. Eng. Part. B J. Eng. Manuf. 2011, 225, 2228-2239. [CrossRef]

31. Baumers, M.; Dickens, P.; Tuck, C.; Hague, R. The cost of additive manufacturing: Machine productivity, economies of scale and technology-push. Technol. Soc. Chang. 2016, 102, 193-201. [CrossRef]

32. Kellens, K.; Renaldi, R.; Dewulf, W.; Kruth, J.P.; Duflou, J.R. Environmental impact modeling of selective laser sintering processes. Rapid Prototyp. J. 2014, 20, 459-470. [CrossRef]

33. BSI. BS ISO 14955-1:2017 Machine Tools_Environmental Evaluation of Machine Tools; BSI: London, UK, 2017.

34. Lobo, L.; Williams, K.; Tyrer, J.R. The use of laser induced processing fume as a process measurand in the feedback control of laser cutting. J. Laser Appl. 2003. [CrossRef]

(C) 2020 by the authors. Licensee MDPI, Basel, Switzerland. This article is an open access article distributed under the terms and conditions of the Creative Commons Attribution (CC BY) license (http://creativecommons.org/licenses/by/4.0/). 